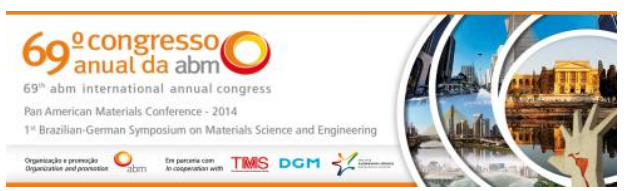

Tema: Soldagem

\title{
ESTUDO DO TRATAMENTO TÉRMICO DE ALÍVIO DE TENSÕES APLICADO EM JUNTAS SOLDADAS POR FCAW DOS AÇOS ASME SA516-70 E ASME SA387-11*
}

\author{
Aprígio Ângelo de Jesus ${ }^{1}$ \\ Danilo Alberto Lima Gomes ${ }^{2}$ \\ Thiago Brion de Assis ${ }^{3}$ \\ Pedro Brito 4
}

\section{Resumo}

No presente trabalho, foram avaliados os efeitos do tratamento térmico de alívio de tensões na microestrutura e propriedades mecânicas de juntas soldadas dos aços SA516-70 e SA387-11 (ambos aplicados na fabricação de vasos de pressão). Chapas com $40 \mathrm{~mm}$ de espessura de ambos os aços foram soldadas por arco elétrico com arame tubular e, posteriormente, submetidas a tratamento térmico para alívio de tensões. A variação de dureza ao longo da solda e a resistência à tração dos materiais soldados e tratados termicamente foi avaliada. A microestrutura dos materiais soldados foi acompanhada por microscopia ótica convencional. Por meio do tratamento térmico empregado foi possível observar a redução do nível de encruamento nos metais base e zonas termicamente afetadas das juntas em ambos os materiais com aumento de ductilidade no aço SA516-70.

Palavras-chave: Soldagem; Tensões residuais; Microestrutura; Propriedades mecânicas.

\section{STRESS RELIEF ANNEALING IN FCAW WELDED JOINTS OF ASME SA516-70 AND ASME SA387-11 STEELS}

\section{Abstract}

In the present work, the effects of stress relief annealing treatment on mechanical properties and microstructure of SA516-70 and SA387-11 welded joints were investigated. Sheets with $40 \mathrm{~mm}$ thickness of both steels were joined by flux-cored arc welding and submitted to heat treatment. The hardness variation along the cross section of welded joints and the tensile properties of the joined materials was evaluated. The microstructure of the heat treated and welded materials was characterized by optical microscopy. By applying the proposed heat treatment, it was possible to reduce strain-hardening caused by the welding induced residual stresses in the base materials and heat affected zones, and an increase in ductility could be observed for the SA516-70 steel.

Keywords: Welding; Residual stresses; Microstructure; Mechanical properties.

1 Engenheiro Mecânico, Departamento de Engenharia Mecânica, Pontifícia Universidade Católica de Minas Gerais (aluno egresso), Belo Horizonte, MG, Brasil.

2 Engenheiro Mecânico, Departamento de Engenharia Mecânica, Pontifícia Universidade Católica de Minas Gerais (aluno egresso), Belo Horizonte, MG, Brasil.

3 Engenheiro Mecânico, Departamento de Engenharia Mecânica, Pontifícia Universidade Católica de Minas Gerais (aluno egresso), Belo Horizonte, MG, Brasil.

4 Dr.-Ing. Msc., Engenheiro Mecânico, Professor Adjunto IV, Departamento de Engenharia Mecânica, Pontifícia Universidade Católica de Minas Gerais, Belo Horizonte, MG, Brasil

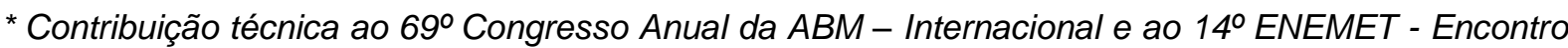
Nacional de Estudantes de Engenharia Metalúrgica, de Materiais e de Minas, 21 a 25 de julho de 2014, São Paulo, SP, Brasil.
} 


\section{MATERIAIS E MÉTODOS}

\subsection{Fabricação das juntas soldadas}

Os materiais empregados para a fabricação das juntas soldadas foram os aços ASME SA516-70 (aço ao carbono) e SA387-11 Classe 2 (aço de alta resistência e baixa liga). A composição química nominal segundo a especificação de norma de ambos os materiais é apresentada na Tabela 1.

Tabela 1. Composição química nominal dos aços utilizados no presente trabalho.

\begin{tabular}{lccccccc}
\hline Aço & $\% \mathrm{C}$ & $\% \mathrm{Mn}$ & $\% \mathrm{P}(\max )$ & $\% \mathrm{~S}(\max )$ & $\% \mathrm{Si}$ & $\% \mathrm{Cr}$ & $\% \mathrm{Mo}$ \\
\hline SA516-70 & 0,28 & $0,79-1,30$ & 0,035 & 0,035 & $0,13-0,45$ & - & - \\
\hline SA387-11 & $0,04-0,17$ & $0,35-0,73$ & 0,035 & 0,035 & $0,44-0,86$ & $0,94-1,56$ & $0,40-0,70$ \\
\hline
\end{tabular}

O corte das chapas, preparação dos chanfros e a soldagem ocorreram nas dependências da Delp Engenharia Mecânica S/A, empresa que forneceu matéria prima, consumíveis de soldagem e mão de obra do soldador. A configuração dos chanfros e as dimensões das chapas utilizadas são apresentadas na Figura 2.

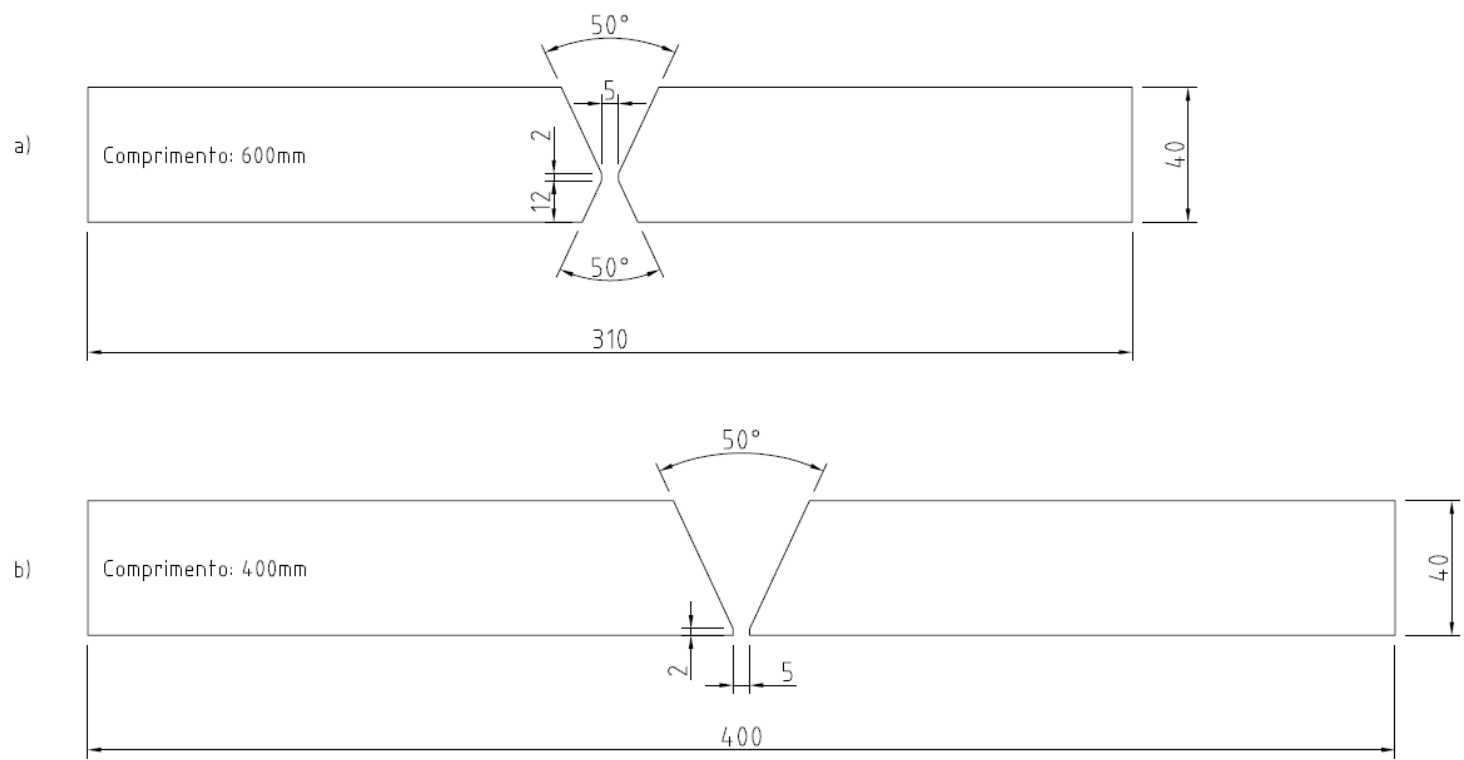

Figura 2. Croqui das juntas soldadas: (a) aço SA516-70 e (b) SA381-11.

As soldas foram executadas pelo processo FCAW (Flux-cored Arc Welding). Na Tabela 2 são apresentados os parâmetros utilizados no processo de soldagem. A aplicação do processo de soldagem em ambos os materiais foi manual, de modo que não foram controladas a velocidade de soldagem, nem a velocidade de alimentação do arame. Os metais de adição SFA 5.20 E71T-1 e SFA5.29 E81T1B2C, indicados na Tabela 2, possuem composição química nominal informada pelo fabricante de Fe-0,05\%C-0,60\%Si-1,20\%Mn e Fe-0,05\%C-0,50\%Si-1,10\%Mn$1,20 \% \mathrm{Cr}-0,55 \% \mathrm{Mo}$, respectivamente.

As chapas de aço SA516-70 tiveram chanfros preparados em " $X$ " (conforme Figura 1). No processo de soldagem, foi feito uso de cobre junta cerâmico no passe de raiz, com intuito de garantir melhor qualidade dos passes iniciais e evitar a completa extração da raiz. O preenchimento ocorreu primeiramente no chanfro maior da chapa (2/3), precedido dos passes de acabamento. Posteriormente, a chapa foi

\footnotetext{
* Contribuição técnica ao $69^{\circ}$ Congresso Anual da ABM - Internacional e ao 14ํㅡㄹ ENEMET - Encontro Nacional de Estudantes de Engenharia Metalúrgica, de Materiais e de Minas, 21 a 25 de julho de 2014, São Paulo, SP, Brasil.
} 


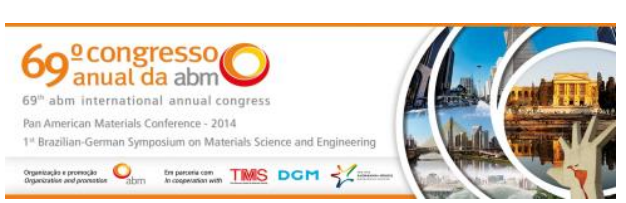

\subsection{Ensaios de Tração}

As curvas de tensão-deformação foram obtidas em uma máquina universal de ensaio de tração EMIC20000 instrumentada com capacidade máxima de 20 toneladas. A velocidade de deformação empregada foi de $2 \mathrm{~mm} / \mathrm{min}$. Os corpos de prova empregados para realização dos ensaios de tração foram retirados da direção transversal da junta e suas dimensões são apresentadas na Figura 3. As condições do ensaio e as dimensões adotadas dos corpos-de-prova seguiram a norma NBR 6152 [6]. Foram preparados 4 corpos-de-prova de cada junta soldada antes do tratamento térmico e 4 corpos-de-prova de cada junta soldada tratados termicamente.

a)

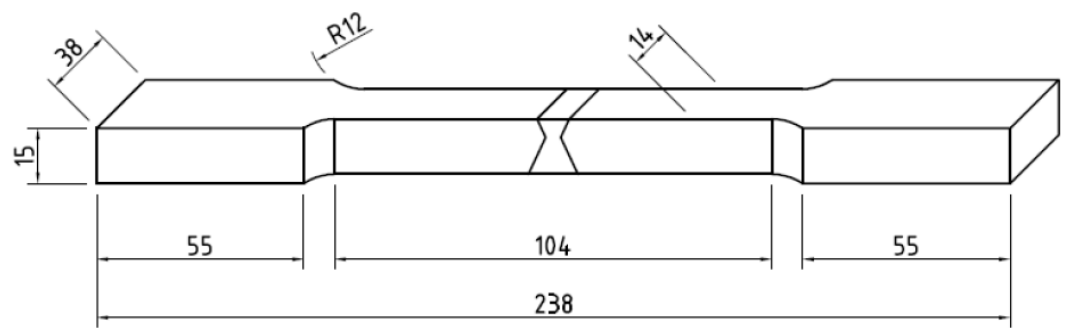

b)

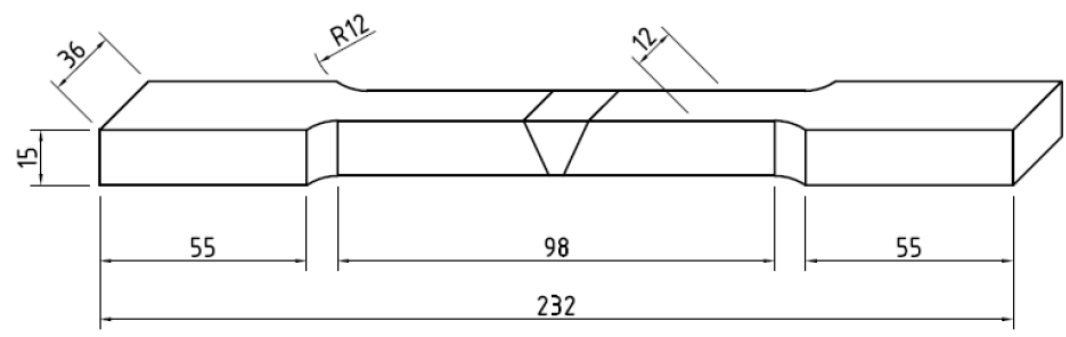

Figura 3. Croqui dos corpos-de-prova utilizados nos ensaios de tração: (a) aço SA516-70 e (b) SA387-11.

\subsection{Ensaios de Dureza}

A variação de dureza ao longo da seção reta das juntas soldadas dos aços SA51670 e SA387-11 antes e após a aplicação do tratamento térmico foi avaliada pelo método Rockwell B. Para cada junta soldada foram feitas medições segundo duas linhas distintas sendo a primeiro localizada a $6 \mathrm{~mm}$ abaixo da face da junta a segunda próxima à raiz da junta, totalizando 16 pontos de medição. Na Figura 4 são apresentadas as posições das linhas de medição em cada corpo-de-prova.
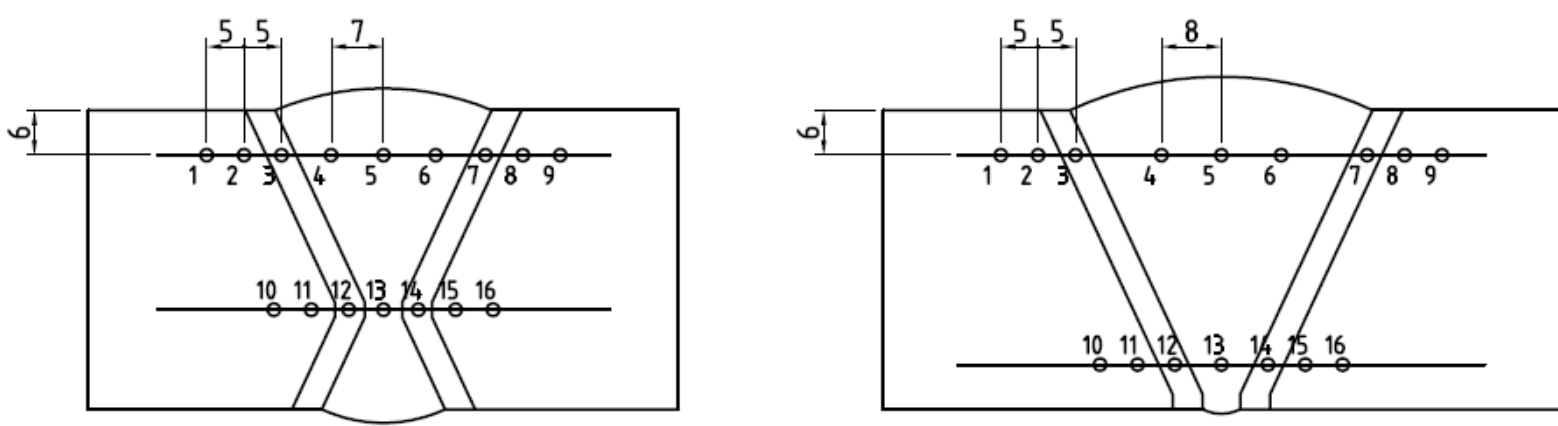

Figura 4. Croqui dos corpos-de-prova utilizados na determinação da variação de dureza ao longo das juntas soldadas (esquerda, chanfro "X": aço SA516-70; direita, chanfro V: aço SA387-11).

* Contribuição técnica ao $69^{\circ}$ Congresso Anual da ABM - Internacional e ao 14ํㅡㄹ ENEMET - Encontro Nacional de Estudantes de Engenharia Metalúrgica, de Materiais e de Minas, 21 a 25 de julho de 2014, São Paulo, SP, Brasil. 


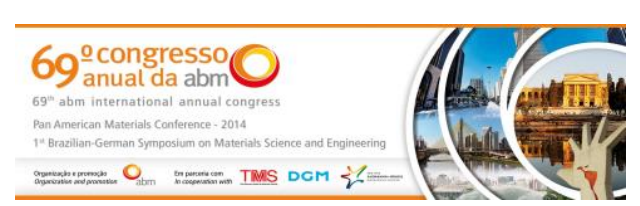

compatível com a especificação. Como se pode perceber pelos resultados apresentados na Figura 5 e resumidos na Tabela 4, o tratamento térmico realizado provocou no aço SA516-70 uma redução na resistência mecânica com aumento na ductilidade. O aço SA387-11 mostrou-se menos sensível ao tratamento térmico, havendo uma ligeira queda de resistência mecânica e um pequeno aumento de ductilidade. Nota-se também que ambos os materiais tiveram comportamento dúctil, uma vez que apresentaram fase plástica extensa com elevada razão entre LRT e LE. O comportamento dúctil também pode ser evidenciado pelo aspecto da fratura, ilustrado na Figura 6 para o aço SA516-70 antes da aplicação do tratamento térmico. As características presentes na Figura 6 que denotam fratura dúctil são formação de estricção, aspecto taça-cone e opacidade da superfície de fratura.

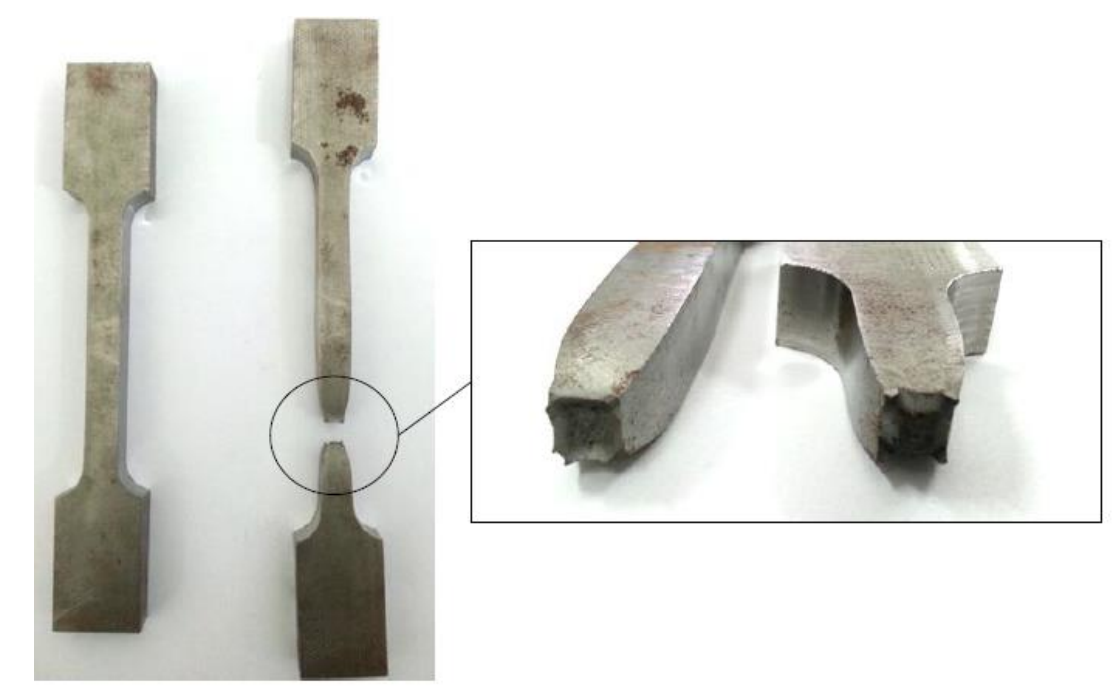

Figura 6. Aspecto macroscópico da fratura do corpo-de-prova submetido a ensaio de tração do aço SA516-70 antes da aplicação do tratamento térmico para alívio de tensões.

\subsection{Variação de Dureza ao Longo da Solda}

Para cada material, antes e após o tratamento térmico para alívio de tensões, foram realizadas medições de dureza HRB. Na Tabela 5 são apresentados os valores médios de dureza para cada aço, antes e após a aplicação de tratamento térmico, para as diferentes regiões da solda: MB, ZTA e ZF. Nas Figuras 7(a) e 7(b) são apresentadas as variações de dureza, respectivamente, ao longo da raiz e do topo da solda, para o aço SA516-70 antes e depois do tratamento térmico. Nas Figuras 8(a) e 8(b) são apresentadas as variações de dureza, respectivamente, ao longo da raiz e do topo da solda, para o aço SA387-11 antes e depois do tratamento térmico. Não se percebeu influência da geometria dos chanfros no processo de alívio de tensões decorrente de tratamento térmico nos materiais. Supostamente, o chanfro em "X" levaria a uma junta soldada com tensões residuais de menor magnitude devido ao equilíbrio dos efeitos de expansão-contração térmica durante a soldagem nas regiões da raiz e da face da junta, com redução de dureza menor após o tratamento térmico, o que não foi observado.

Como se pode perceber pelos resultados apresentados nas Figuras 7 e 8 , há uma distribuição heterogênea de durezas entre a face e raiz da junta com a tendência de maior endurecimento nas regiões superiores da solda. Isso pode ser explicado pelo fato de que os cordões depositados próximos à raiz foram reaquecidos pela

\footnotetext{
* Contribuição técnica ao $69^{\circ}$ Congresso Anual da ABM - Internacional e ao 14ํㅡㄹ ENEMET - Encontro Nacional de Estudantes de Engenharia Metalúrgica, de Materiais e de Minas, 21 a 25 de julho de 2014, São Paulo, SP, Brasil.
} 


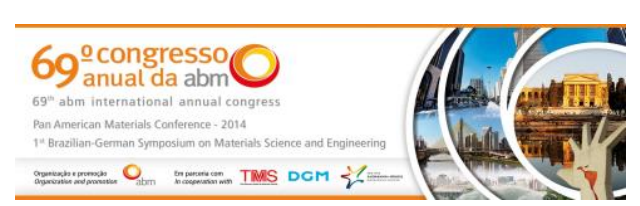

\subsection{Ensaios Metalográficos}

As microestruturas formadas na ZF das juntas soldadas dos aços SA516-70 e SA387-11 são apresentadas, respectivamente, nas Figuras 9 e 10. A ZF do aço SA516-70 é constituída de ferrita primária e perlita. Comparando as Figuras 9(a) e 9(b), que apresentam as microestruturas antes e após o tratamento térmico, respectivamente, se pode perceber que a estrutura dos grãos pode ser mais facilmente delineada na Figura $9(\mathrm{~b})$ o que pode indicar a ocorrência de recristalização na ZF, justificando a queda de dureza apresentada na Figura 7.
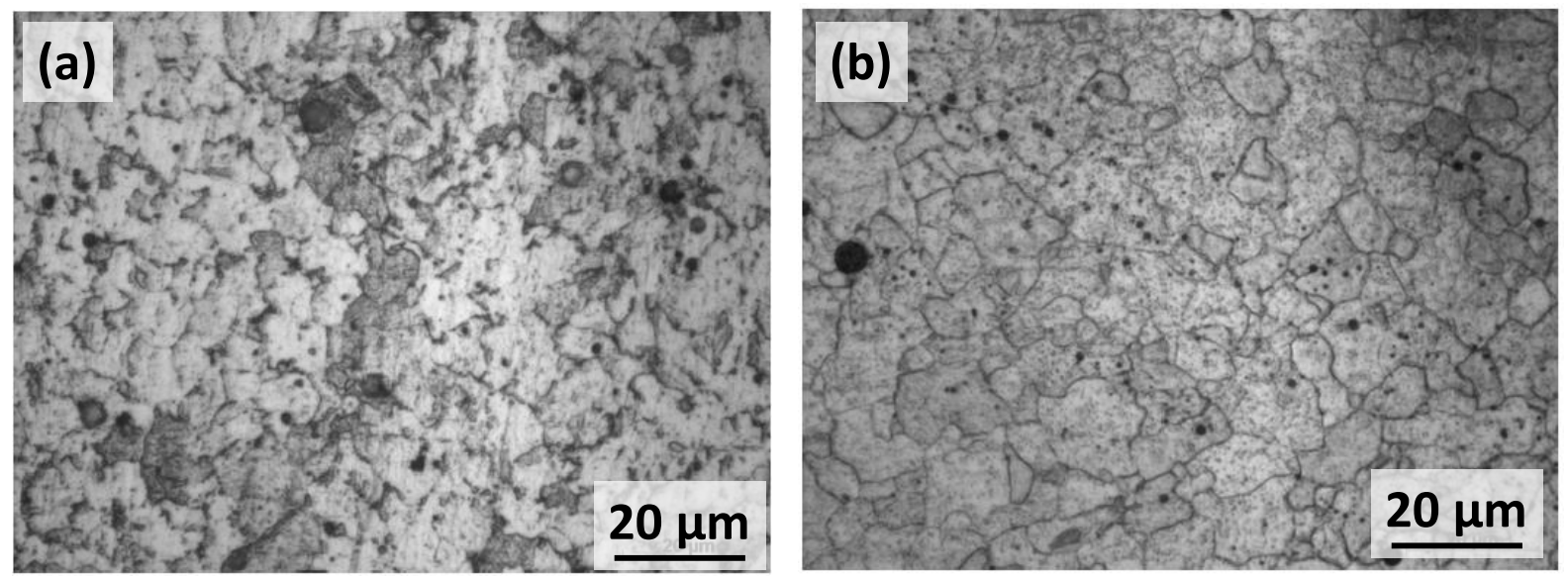

Figura 9. Micrografias da ZF da junta soldada do aço SA516-70: (a) antes do tratamento térmico e (b) após o tratamento térmico.
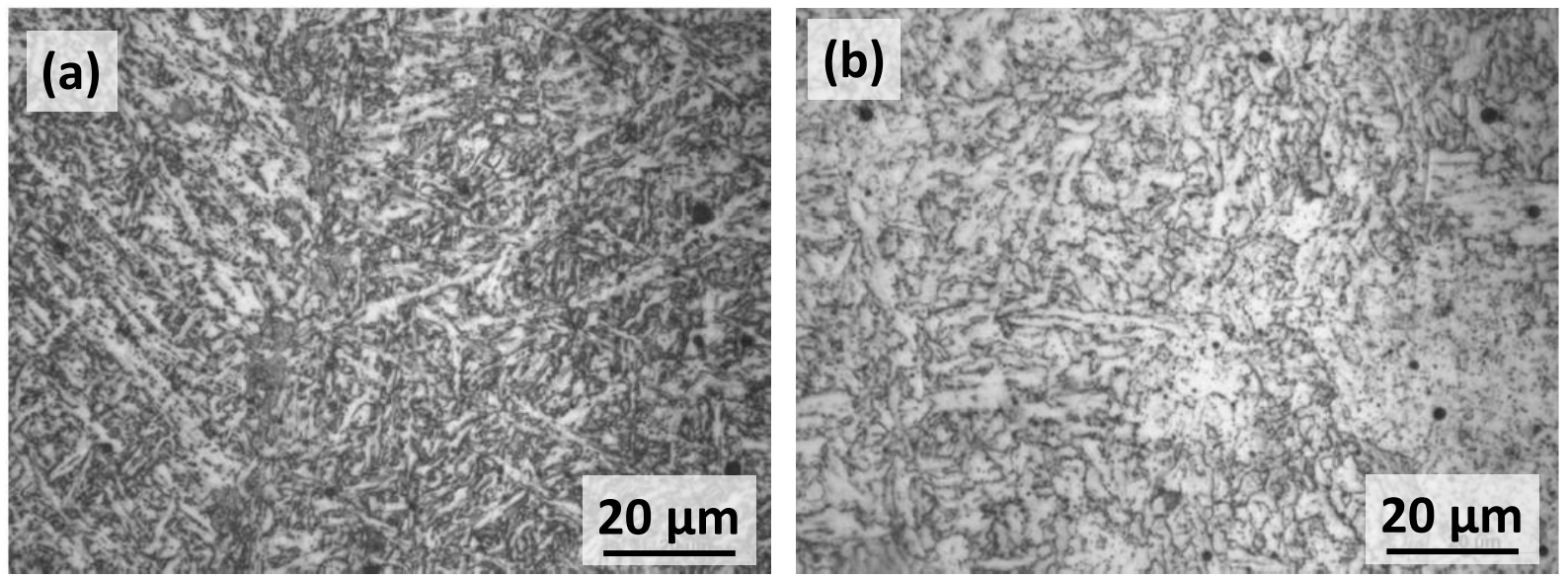

Figura 10. Micrografias da ZF da junta soldada do aço SA387-11: (a) antes do tratamento térmico e (b) após o tratamento térmico.

A microestrutura da ZF da junta soldada do aço SA387-11, apresentada nas Figuras 10(a) e 10(b), conta com a presença de ferrita acicular, em conformidade com resultados de estudos anteriores [8]. A elevada densidade de discordâncias e a presença de contornos de grão de alto ângulo na ferrita acicular provoca aumento de dureza em relação à ferrita primária. Uma vez que o tratamento térmico aplicado no presente trabalho foi efetuado abaixo da temperatura de austenitização dos materiais, não houve eliminação desse microconstituinte, que pode ser identificado na Figura 10(b). Assim, não se observa queda de dureza acentuada ao longo de

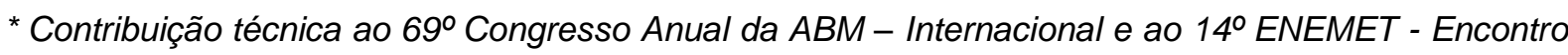
Nacional de Estudantes de Engenharia Metalúrgica, de Materiais e de Minas, 21 a 25 de julho de 2014, São Paulo, SP, Brasil.
} 


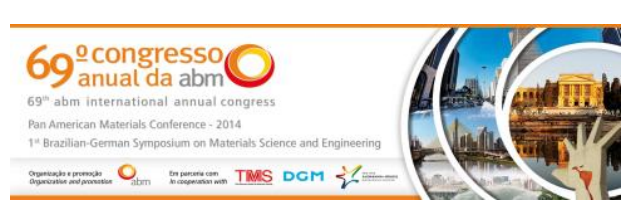

toda ZF do aço SA387-11. Em contraste, por exemplo, no trabalho de Trindade Filho e colegas [2], foi possível observar redução significativa de resistência mecânica em soldas de aços de alta resistência pela eliminação de ferrita acicular, o que foi obtido com tratamento de normalização seguido de resfriamento lento, levando a uma estrutura de ferrita equaxial. Não se deve descartar a possibilidade de formação de martensita no resfriamento após a soldagem, devido à presença de $\mathrm{Cr}$ e Mo no aço, que deslocam as curvas de transformação para a direita favorecendo a formação dessa fase dura. As regiões em que eventualmente houve a formação de martensita apresentariam dureza mais elevada na ZF, como mostrado na Figura 7(a). Essas regiões, ao contrário das dominadas pela presença de ferrita acicular, tenderiam a mostrar queda de dureza com o tratamento térmico proposto, que levaria então à formação de martensita revenida.

\section{CONCLUSÃo}

No presente realizou-se a soldagem por FCAW de chapas com espessura de $40 \mathrm{~mm}$ dos aços SA516-70 e SA387-11 e os correspondentes tratamentos térmicos para alívio de tensões. Foi possível constatar que para ambos materiais o tratamento térmico levou à redução da dureza dos metais base e zonas termicamente afetadas. Com relação à zona fundida, observou-se redução de dureza apenas para o aço SA516-70. A análise da microestrutura da zona fundida do aço SA387-11 revelou a presença de ferrita acicular na junta soldada, a qual permaneceu após o tratamento térmico, justificando a manutenção da dureza elevada na região central da solda.

\section{Agradecimentos}

Os autores do trabalho agradecem a Delp Engenharia Mecânica S/A que providenciou o corte das chapas, preparação dos chanfros e execução dos procedimentos de soldagem.

\section{REFERÊNCIAS}

1 Marques PV, Modenesi PJ, Bracarense AQ. Soldagem - Fundamentos e Tecnologia. 3ed. Belo Horizonte: Editora UFMG; 2009.

2 Trindade Filho VB, Guimarães AS, Payão Filho JC, Paranhos RPR. Normalizing Heat Treatment Effect on Low Alloy Steel Weld Metals. Journal of the Brazilian Society of Mechanical Science and Engineering. 2004; 26(1): 62-66.

3 Pyzalla AR, Internal Stresses in Engineering Materials, in: Reimers W, Pyzalla AR, Schreyer A, Clemens $\mathrm{H}$, Neutrons and Synchrotron Radiation in Engineering Materials Science, Weinheim: Wiley-VCH.; 2008.

4 Rodrigues TV. Tratamento térmico pós-soldagem para alívio de tensões residuais em chapas de aço soldadas: modelagem e análise experimental. Rio de Janeiro: Centro Federal de Educação Tecnológica do Rio de Janeiro; 2011.

5 ASME - American Society of Mechanical Engineeers. VIII: division 1: rules for construction of pressure vessels. Nova lorque: ASME; 2010.

6 ABNT - Associação Brasileira de Normas Técnicas. Materiais metálicos - ensaio de tração à temperatura ambiente. Rio de Janeiro: ABNT; 2012.

7 NORSOK. Common requirements - Welding Inspection of Piping. Noruega: 1994.

8 Vieira LA, Avaliação da tenacidade após tratamento térmico de alívio de tensões em soldas produzidas com arames tubulares rutílicos que contenham níquel. Belo Horizonte: Universidade Federal de Minas Gerais; 2006.

\footnotetext{
* Contribuição técnica ao $69^{\circ}$ Congresso Anual da ABM - Internacional e ao 14ํㅡㄹ ENEMET - Encontro Nacional de Estudantes de Engenharia Metalúrgica, de Materiais e de Minas, 21 a 25 de julho de 2014, São Paulo, SP, Brasil.
} 